\title{
GIP receptor antagonist treatment causes weight loss in ovariectomized high fat diet-fed mice
}

\author{
Geke Aline Boer ${ }^{1}$, Jenna Hunt ${ }^{1}$, Maria Gabe ${ }^{1}$, Johanne Windel $\varnothing v^{1}$, Alexander \\ Sparre-Ulricht ${ }^{2}$, Bolette Hartmann ${ }^{3}$, Jens Holst ${ }^{1}$, and Mette Rosenkilde ${ }^{4}$ \\ ${ }^{1}$ University of Copenhagen \\ ${ }^{2}$ Antag Therapeutics ApS \\ ${ }^{3}$ Novo Nordisk, A/S \\ ${ }^{4}$ University of Copenhagen
}

June 7, 2021

\begin{abstract}
Background and purpose The incretin hormone, glucose-dependent insulinotropic polypeptide (GIP), secreted by the enteroendocrine K-cells in the proximal intestine, may regulate lipid metabolism and adiposity but its exact role in these processes is unclear. Experimental approach We characterized in vitro and in vivo antagonistic properties of a novel GIP analogue, mGIPAnt-1. We further assessed the in vivo pharmacokinetic profile of this antagonist, as well as its ability to affect high-fat diet (HFD)-induced body weight gain in ovariectomized mice during an 8-week treatment period. Key results mGIPAnt-1 showed competitive antagonistic properties to the GIP receptor (GIPR) in vitro as it inhibited GIP-induced cAMP accumulation in COS-7 cells. Furthermore, mGIPAnt-1 was capable of inhibiting GIP-induced glucoregulatory and insulinotropic effects in vivo and has a favourable pharmacokinetic profile with a half-life of 7.2 hours in C57Bl6 female mice. Finally, sub-chronic treatment with mGIPAnt-1 in ovariectomized HFD mice resulted in a reduction of body weight and fat mass. Conclusion and Implications mGIPAnt-1 successfully inhibited acute GIP-induced effects in vitro and in vivo and sub-chronically induces resistance to HFD-induced weight gain in ovariectomized mice. Our results support the development of GIP antagonists for the therapy of obesity.
\end{abstract}

\section{Hosted file}

mGIPant manuscript_GAB_BJP_Final.pdf available at https://authorea.com/users/418275/articles/ 525077-gip-receptor-antagonist-treatment-causes-weight-loss-in-ovariectomized-high-fatdiet-fed-mice 
A

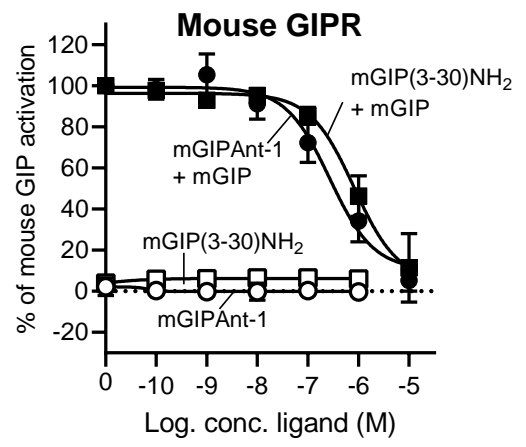

B

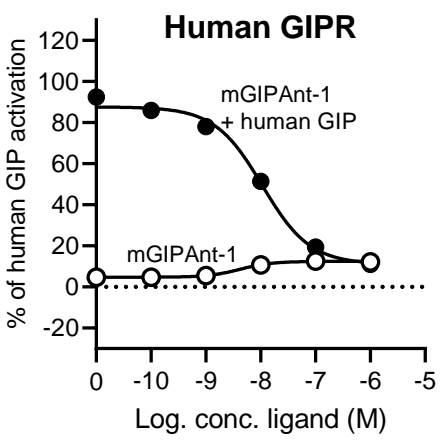



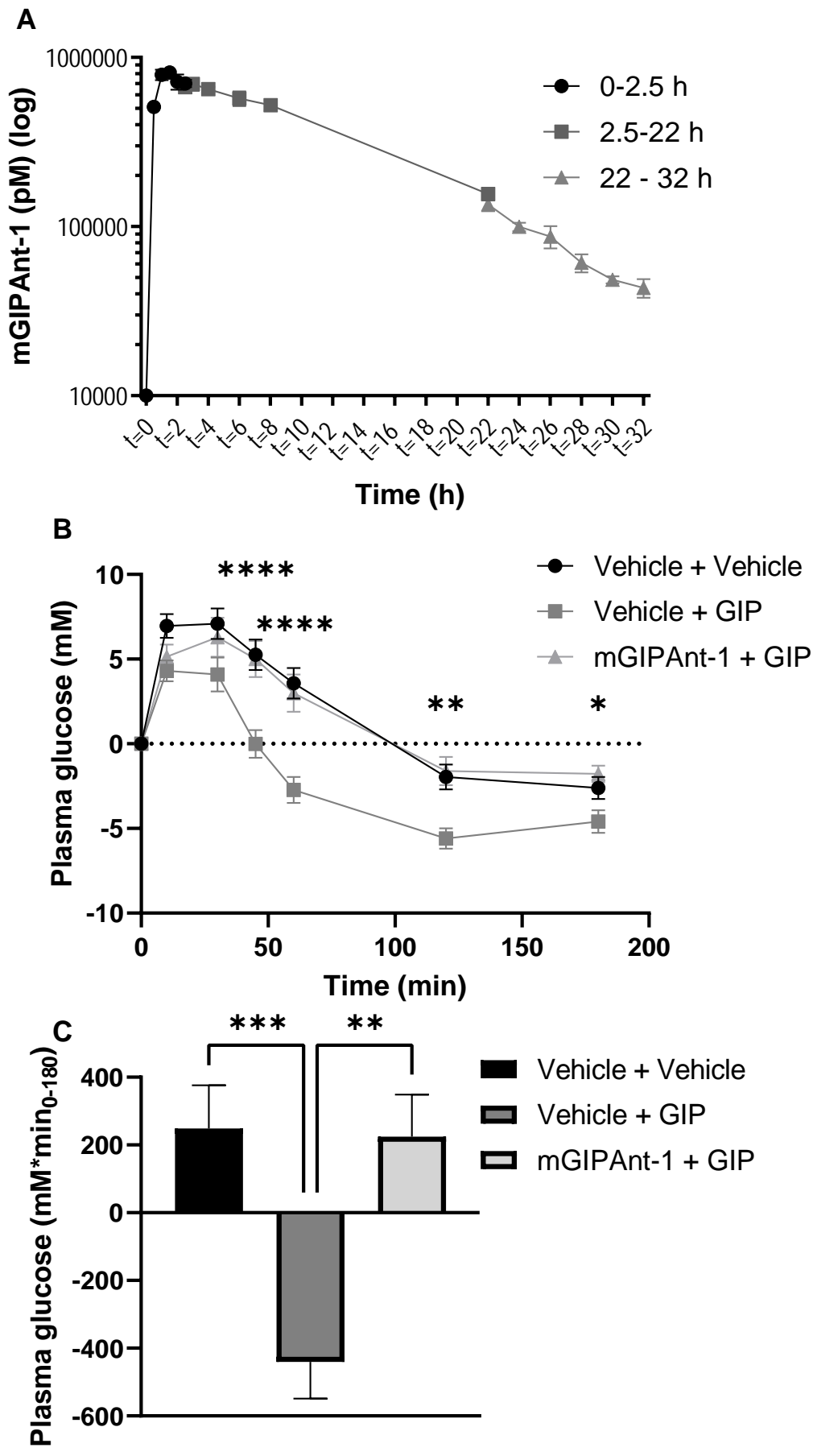

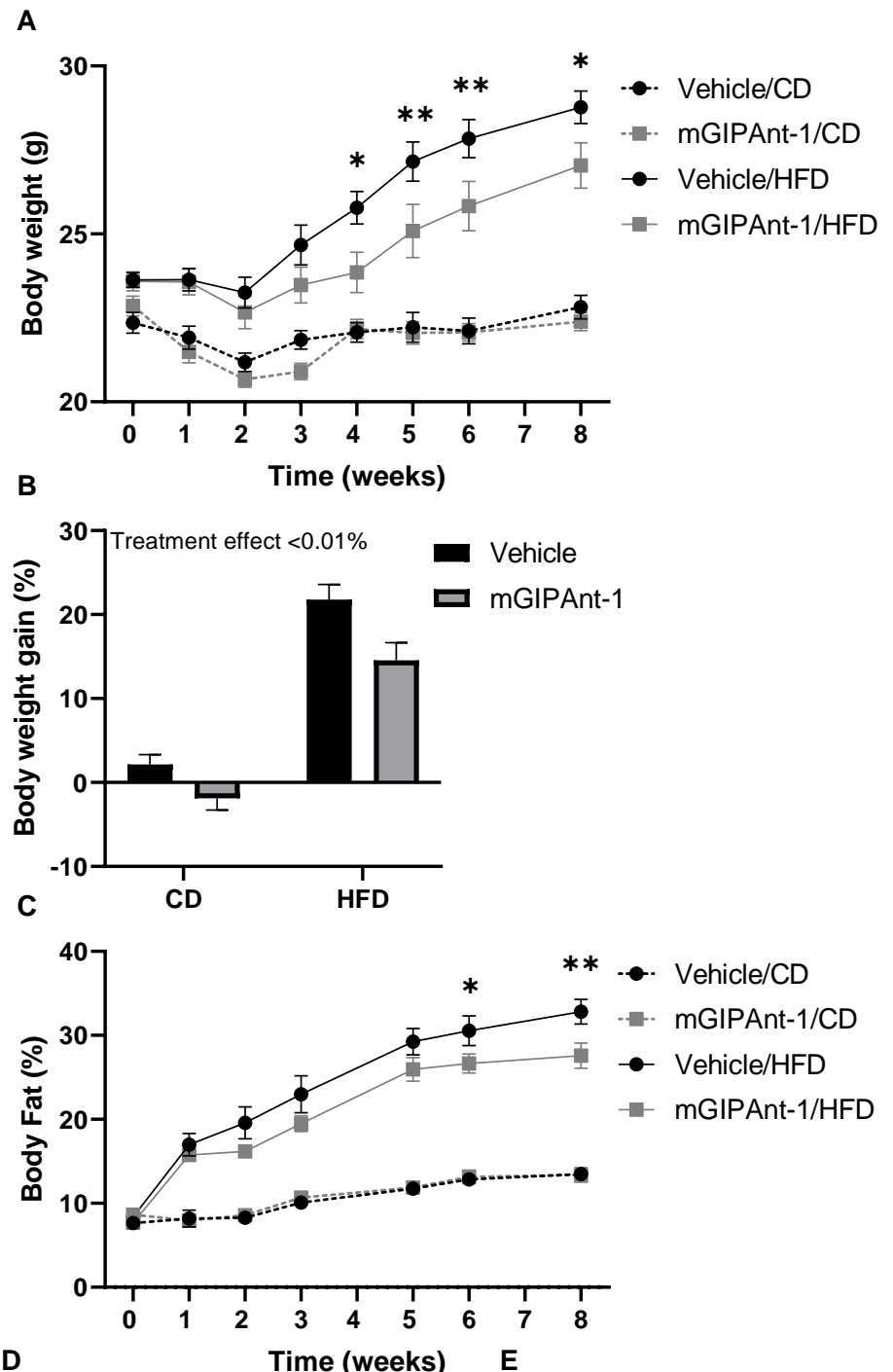

D
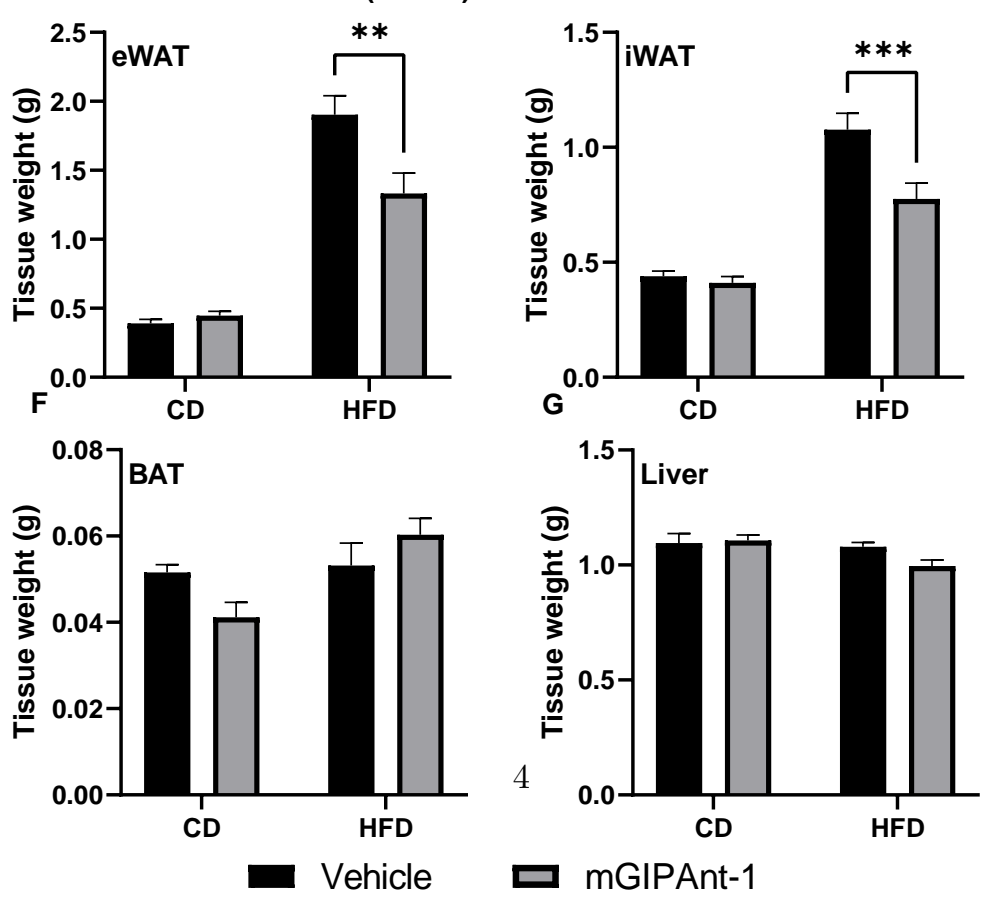
A
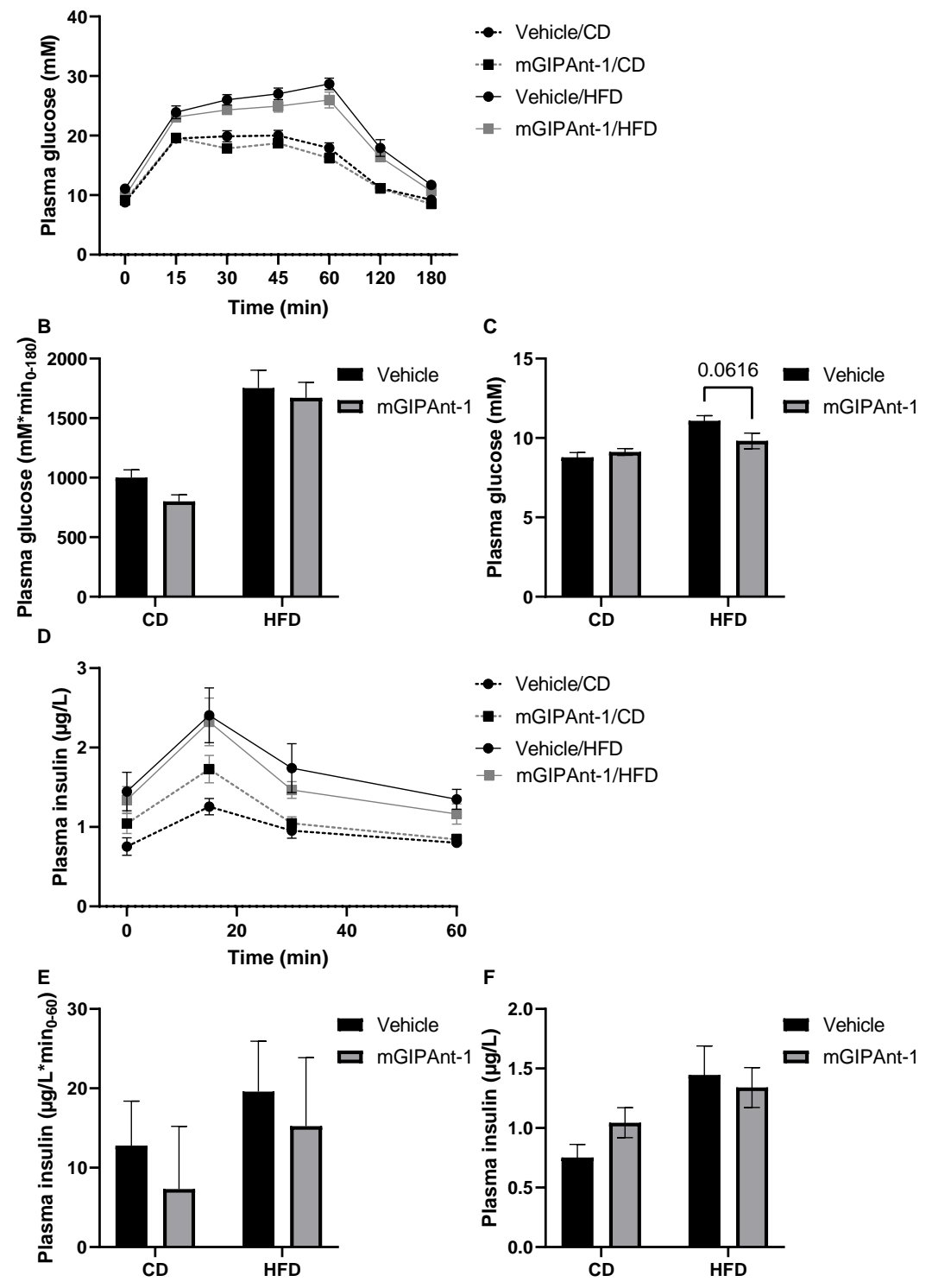

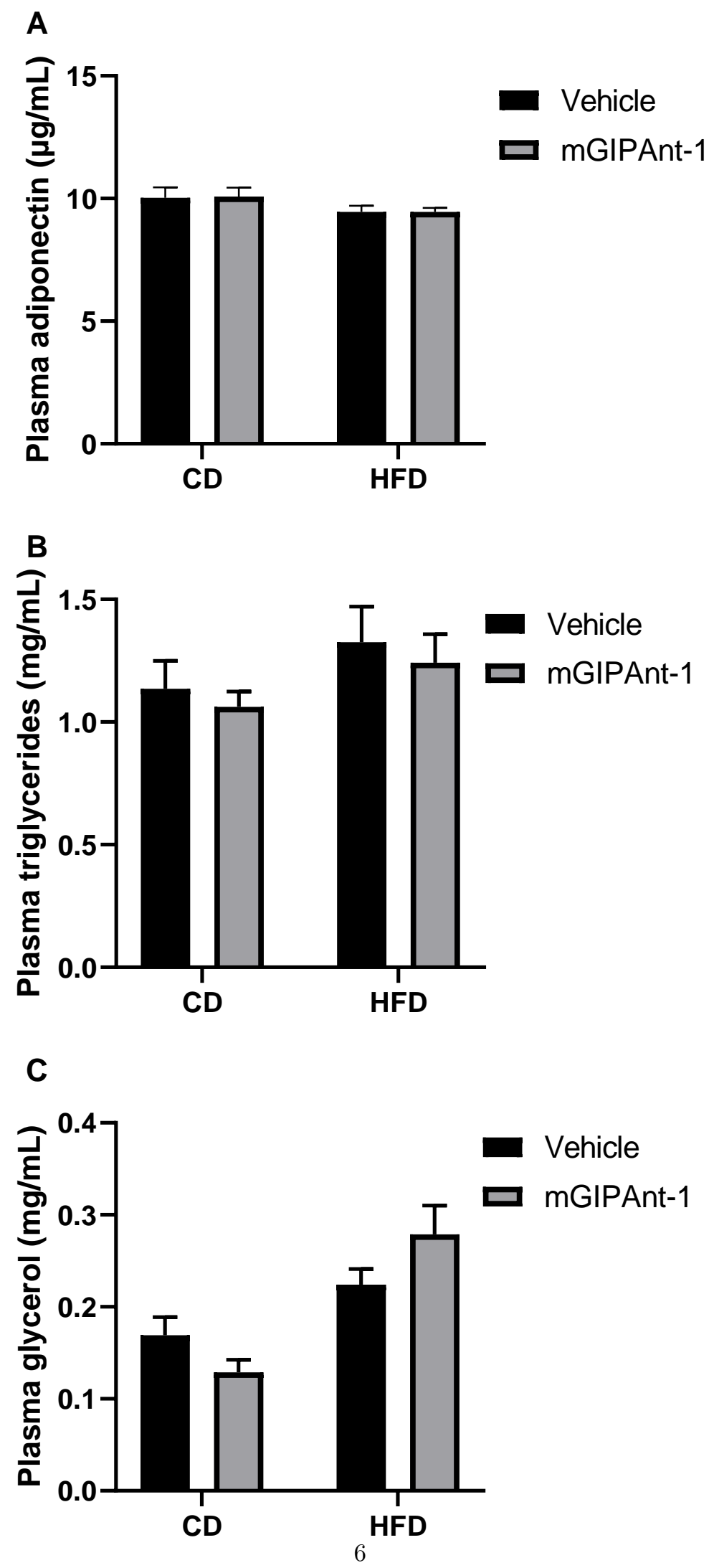